\title{
CT-guided transthoracic biopsies of lung lesions suspected of malignancy
}

\author{
M. D. Guimarães · J. L. Gross • A. G. V. Bitencourt • \\ R. Chojniak
}

Received: 17 December 2012/ Accepted: 6 January 2013/Published online: 16 January 2013

(C) Royal Academy of Medicine in Ireland 2013

We would like to congratulate Schweigert et al. [1] for the interesting study concerning the diagnostic and therapeutic approach to pulmonary infections mimicking lung cancer recently published in the 2012 issue of the Irish Journal of Medical Science. In this study, all patients were referred to a thoracic surgeon because of a suspicion of lung malignancy. Video-assisted thoracoscopic wedge resection was performed in 6 cases, lobectomy in 5 cases and videoassisted thoracoscopic lobectomy and open wedge resection in one case each; adequate samples were recovered for specific diagnosis. However, with the technical advances in computed tomography (CT)-guided transthoracic needle biopsy (TNB) in the last two decades, this procedure has become a reliable technique for lung lesion diagnosis. It has several advantages including lower cost, lower morbidity and can be performed in an outpatient setting under local anesthesia [2]. Moreover, patients with benign lesions and those with metastatic tumors should not be exposed to perilous invasive procedures. A body of literature shows that CT-guided TNB has improved the diagnostic yields and decreased the risks of complications [3]. Cutting rather than fine needles should be selected to obtain specific diagnosis for both benign and malignant lesions [2, 4]. Chojniak et al. demonstrate that for lung lesions, sample adequacy and specificity were always better for the cuttingneedle biopsy with rates of 95 and $82 \%$, respectively. Fine needle aspiration biopsy yielded statistically smaller rates of 88 and $67 \%$, respectively $(p<0.05)$ [5].

CT-guided cutting-needle biopsy is an effective and safe method for diagnosing lung lesions. Whenever feasible, it should be indicated for therapeutic planning because it offers the possibility of avoiding an invasive procedure for both benign lesions and advanced malignancy.

Conflict of interest None.

\section{References}

1. Schweigert M, Dubecz A, Beron M, Ofner D, Stein HJ (2012) Pulmonary infections imitating lung cancer: clinical presentation and therapeutical approach. Ir J Med Sci 182(1):73-80

2. Guimaraes MD, de Andrade MQ, da Fonte AC, Chojniak R, Gross JL (2011) CT-guided cutting needle biopsy of lung lesions-an effective procedure for adequate material and specific diagnose. Eur J Radiol 80:e488-e490

3. Yuan DM, Lü YL, Yao YW et al (2011) Diagnostic efficiency and complication rate of CT-guided lung biopsy: a single center experience of the procedures conducted over a 10-year period. Chin Med J (Engl) 124:3227-3231

4. Beslic S, Zukic F, Milisic S (2012) Percutaneous transthoracic CT guided biopsies of lung lesions; fine needle aspiration biopsy versus core biopsy. Radiol Oncol 46:19-22

5. Chojniak R, Isberner RK, Viana LM, Yu LS, Aita AA, Soares FA (2006) Computed tomography guided needle biopsy: experience from 1,300 procedures. Sao Paulo Med J 124:10-14

M. D. Guimarães $(\bowtie)$ · A. G. V. Bitencourt · R. Chojniak

Department of Imaging, Hospital A.C. Camargo,

R. Professor Antônio Prudente, 211,

CEP 01509-010 São Paulo, Brazil

e-mail: marcosduarte500@gmail.com

J. L. Gross

Department of Thoracic Surgery,

Hospital AC Camargo, São Paulo, Brazil 